\title{
ELECTROCHEMICAL OXIDATION-REDUCTION PATHS FOR PYRIMIDINE, CYTOSINE, PURINE AND ADENINE
}

\author{
CORRELATION AND APPLICATION
}

\author{
GLENN DRYHURST \\ University of Oklahoma, Norman, Oklahoma \\ and \\ Philip J. Elving \\ University of Michigan, Ann Arbor, Michigan
}

(Received 6 January 1969. Accepted 27 February 1969)

\begin{abstract}
Summary-In order to evaluate the striking discrepancy between the experimental ease of polarographic reduction of adenine and cytosine, and that predicted by molecular orbital calculation, the electrochemical oxidation-reduction behaviour of pyrimidine, cytosine, purine, adenine and related compounds was investigated at both mercury and graphite electrodes. Information was obtained on the specific adsorption of reactant and product species on the electrode, the reversibility of the energy-controlling elcctron-transfer step, and accompanying chemical reactions. Triangular sweep voltammetry, a.c. and d.c. polarography, and electrocapillary data, in particular, were utilized. The first three techniques were critically examined for their potential analytical utility. The results were compared with previously obtained electrochemical data and the sequence of electron-transfer and various nonelectron transfer steps was more firmly established. It became clear that in order validly to correlate quantum mechanically calculated data for the energy required to add or remove an electron to or from the outermost electron level of each molecule (in the gas phase), with electrochemical redox potentials (in solution), the effects of adsorption, electron-transfer reversibility and solvation energy must be considered.
\end{abstract}

CONSIDERATION of the conditions under which many electrochemical and biological transformations occur indicates that there should be a distinct parallelism between the two processes. Both electrolytic redox processes and, for example, enzymatic transformations involve heterogeneous electron-transfer as well as similar mass transport modes, and solvent, temperature and ionic strength effects; both processes also have stereochemical requirements that must be met before electron transfer can occur. Accordingly, it should be possible to correlate the pathways for the electrolytic breakdown of biologically important molecules (such as the purines and pyrimidines) with the characteristic potentials associated with these processes, with pathways for biological transformations, and with theoretically calculated energies for the energy-determining initial electron transfer in redox reactions. Struck and Elving found that analogous mechanisms must be postulated to explain the enzymatic ${ }^{2}$ and electrochemical oxidations of uric acid, and Dryhurst and Elving ${ }^{3}$ found that adenine (6-aminopurine) is electrolytically oxidized at the pyrolytic graphite electrode (PGE) by a mechanism that initially follows the enzymatic path. ${ }^{4,5}$ (The

* The purine and pyrimidine ring numbering advocated by Chemical Abstracts has been followed. The commonly accepted formulas are used; allowance may have to be made in some cases for alteration due to keto-enol and acid-base equilibria. 
duration of the latter oxidation indicated that intermediate chemical or other nonelectron transfer processes were involved; part of the work described in the present study is aimed at elucidating the roles of these effects.)

Quantum mechanical calculations ${ }^{6.7}$ indicate that, of the fundamental purines and pyrimidines found in nucleic acids, cytosine should be the most readily reduced. Predictions based on such calculations are, however, at best only in approximate accord with experimentally observed polarographic reduction half-wave potentials $\left(E_{1 / 2}\right)$ or voltammetric oxidation half-peak $\left(E_{\mathrm{p} / 2}\right)$ or peak $\left(E_{\mathrm{p}}\right)$ potentials. An obvious anomaly is the fact that cytosine (2-oxo-4-aminopyrimidine) is polarographically reduced at a more negative potential than is adenine. Because of this anomaly and the fundamental role that cytosine and adenine play in many biochemical processes, it was decided to examine in some detail the electrochemical behaviour of these compounds and their parent and related purines and pyrimidines. In particular, it was felt that the roles of adsorption of reactants and products at the electrode, reversibility of the electron-transfer step, and solvation energies should be at least qualitatively evaluated, since these effects influence the potential associated with the processes and probably, therefore, the mechanistic route.

In order more fully to understand electrochemical redox mechanisms and their relationship to biological transformations, it is necessary to ascertain qualitatively and, where possible, quantitatively the involvement of specific electrode-substrate phenomena, such as adsorption-desorption effects on the electrode surface and substrate-electrode reactions, which are not present in biological systems and which may, unless taken into account, invalidate correlations of biological and electrochemical data.

The electrochemical behaviour of purines and pyrimidines with stress on their polarography and voltammetry has been reviewed ${ }^{8}$. The compounds of interest in the present study have been investigated ${ }^{9-12}$ by single-sweep direct-potential slowscan polarography and voltammetry at the dropping mercury electrode (DME) and the pyrolytic graphite electrode (PGE). The present study utilized predominantly cyclic voltammetry at the PGE and at the hanging mercury drop electrode (HMDE). Alternating current polarography and electrocapillary curves at the DME were used to study adsorption phenomena; the former was also employed to evaluate the reversibility of various processes.

Cyclic voltammetric behaviour

Purine, adenine, pyrimidine and cytosine were examined; scan rates were generally 0.06 and 0.6 $\mathrm{V} / \mathrm{sec}$ at the PGE and 0.026 and $0.26 \mathrm{~V} / \mathrm{sec}$ at the HMDE.

Pyrimidine at HMDE. Between $\mathrm{pH} 0$ and $4 \cdot 6$, pyrimidine gives a single $\mathrm{pH}$-dependent peak (peak I, Table I). A second, less $\mathrm{pH}$-dependent peak (II) appears between $\mathrm{pH} 4 \cdot 6$ and 5.5. Above $\mathrm{pH} 4.7$ peak II is smaller than peak I, indicating a short-lived peak I product. Above $\mathrm{pH} 6, \mathrm{pH}$ dependent peak III appears, with current about twice that of peak I. At pH 8, peak IV appears, and at $\mathrm{pH} 9$ peak $\mathrm{V}$ appears as a slight inflection on background discharge so that accurate evaluation of its potential and current is difficult; its current is about four times that of peak I.

At $\mathrm{pH} 1.05, i_{\mathrm{p}} / A C$, for peak $\mathrm{I}$ is constant at both scan rates (Table II); $i_{\mathrm{p}}$ is the peak current, $A$ the electrode area and $C$ the concentration.

Pyrimidine at $P G E$. Pyrimidine shows a single reduction peak in the $\mathrm{pH}$ range $0-8$ at $0.06 \mathrm{~V} / \mathrm{sec}$ and $\mathrm{pH} 0-6$ at $0.6 \mathrm{~V} / \mathrm{sec}$ scan rate. The $\mathrm{pH}$-dependence of $E_{\mathrm{p}}$ at $0.06 \mathrm{~V} / \mathrm{sec}$ scan rate seems to change at $\mathrm{pH} 4$ with an additional shift at about $\mathrm{pH}$ 6; however, since these effects are small $\left(\Delta E_{\mathrm{p}} / \Delta \mathrm{pH}=\right.$ -0.123 for peak I and -0.091 for peak II) and reproducibility of $E_{\mathrm{p}}$ at the PGE is about $\pm 25 \mathrm{mV}$, $E_{\mathrm{p}}$ may be linearly dependent on $\mathrm{pH}$. At the lower scan rate, $i_{\mathrm{p}}$ is constant between $\mathrm{pH} 1$ and $4 \cdot 6$, but then gradually increases; at $0.60 \mathrm{~V} / \mathrm{sec}, i_{\mathrm{p}}$ is fairly constant. The apparent increase above $\mathrm{pH}$ 5-6 at both scan rates is due, at least in part, to the closeness to background discharge and the consequent difficulty in accurately evaluating the current. 
TABle I.-LINEAR $E_{\mathrm{p}} v s . \mathrm{pH}$ RELATIONSHIPS FOR PURINE, ADENINe, PYRIMIDINE AND CYTOSINE ON CYCLIC VOLTAMMETRY

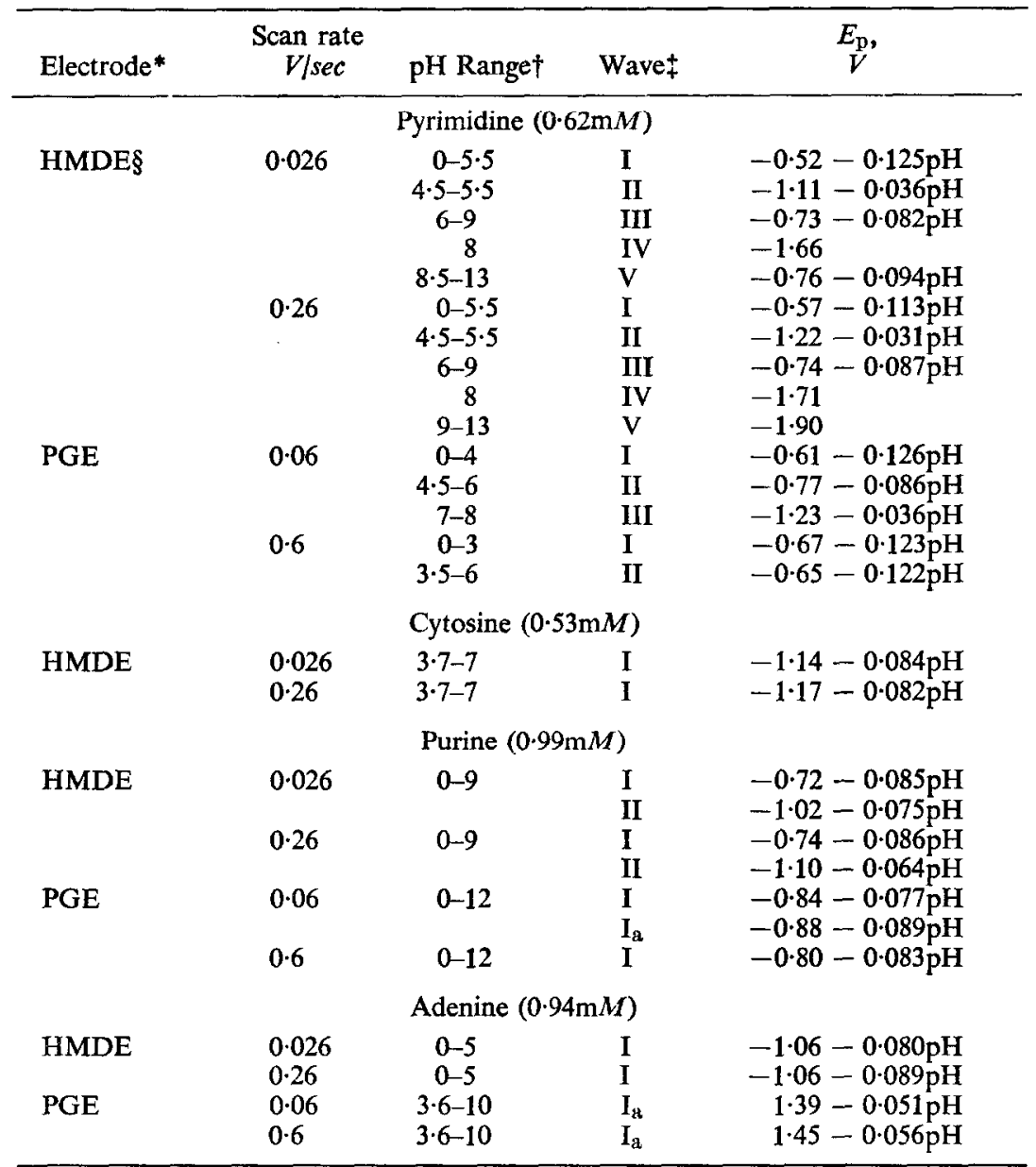

* Electrode areas unless otherwise specified: PGE, $11 \mathrm{~mm}^{2}$; HMDE, $5 \mathrm{~mm}^{2}$.

$\dagger$ Ionic strength $0.5 M$.

$¥$ Subscript a refers to an anodic wave; the other waves are cathodic.

$\S$ Area of HMDE electrode was $0.6 \mathrm{~mm}^{2}$.

No evidence for reversibility of the processes was seen on fast scan $(36 \mathrm{~V} / \mathrm{sec})$ cyclic voltammetry. At $\mathrm{pH} 1 \cdot 0, i_{\mathrm{p}} / A C$ is constant (Table II).

Cytosine at HMDE. Cytosine shows a single reduction peak of almost constant $i_{\mathrm{p}}$ between $\mathrm{pH} \mathrm{3.7}$ and 7; $E_{\mathrm{p}}$ varies linearly with $\mathrm{pH}$ (Table 1). At $0.026 \mathrm{~V} / \mathrm{sec}$ scan rate, point-by-point subtraction of background is necessary in order to characterize the peak; at the higher scan rate, the peak is remarkably well-formed. At $\mathrm{pH} 4 \cdot 6, i_{\mathrm{p}}$ increases linearly with concentration, although the $i_{\mathrm{p}} / A C$ ratio decreases (Table II).

There was no evidence for unstable electroactive intermediates at scan rates of up to $200 \mathrm{~V} / \mathrm{sec}$. Cytosine showed no electrochemical activity at the PGE.

Purine at HMDE. Purine shows two well-formed cathodic peaks of constant and very reproducible peak current between $\mathrm{pH} 1$ and 8; peak II disappears at higher $\mathrm{pH}$ and peak I disappears above pH 9; peak potentials varied linearly with pH (Table I). No evidence for an anodic process was observed on the return scan at either rate. At $\mathrm{pH} 4 \cdot 6$, linear $i_{p}-C$ relationships were observed for both peak I and the sum of peaks I and II, although the $i_{\mathrm{p}} / A C$ ratio for peak II decreased somewhat with increasing concentration (Table II). 
TABLE II.-VARIATION OF PEAK CURRENT WITH CONCENTRATION FOR PYRIMIDINE, CYTOSINE, PURINE AND ADENINE ON CYCLIC VOLTAMMETRY AT HMDE AND PGE

\begin{tabular}{|c|c|c|c|c|c|c|}
\hline Electrode & $\begin{array}{l}\text { Area, } \\
m m^{2}\end{array}$ & $\begin{array}{l}\text { Compound } \\
\text { (medium) }\end{array}$ & $\begin{array}{l}\text { Concn. } \\
\text { range,* } \\
m \mathrm{M}\end{array}$ & $\begin{array}{c}\text { Scan-rate } \\
\text { V/sec }\end{array}$ & $\begin{array}{c}\text { Average } \\
\text { current } \\
\text { range, } \dagger \\
\mu A\end{array}$ & $\begin{array}{l}i_{\mathrm{p}} / A C \\
\text { range } \ddagger\end{array}$ \\
\hline \multirow[t]{9}{*}{ HMDE } & $6 \cdot 50$ & Pyrimidine & $0 \cdot 115-1 \cdot 15$ & 0.026 & $0 \cdot 96-10 \cdot 3$ & $1 \cdot 54 \pm 0 \cdot 12$ \\
\hline & & (pH 1.05 chloride) & & $0 \cdot 26$ & $3 \cdot 2-30 \cdot 7$ & $4 \cdot 61 \pm 0 \cdot 10 \S$ \\
\hline & $5 \cdot 33$ & $\begin{array}{l}\text { Cytosine } \\
\text { (pH } 4.6 \text { acetate) }\end{array}$ & $0 \cdot 106-1 \cdot 06$ & $\begin{array}{l}0 \cdot 026 \\
0 \cdot 26\end{array}$ & $\begin{array}{l}3 \cdot 3-24 \cdot 2 \\
8 \cdot 8-58\end{array}$ & $\begin{array}{r}5 \cdot 5 \pm 0 \cdot 7 \S \\
17-119\end{array}$ \\
\hline & $5 \cdot 33$ & $\begin{array}{l}\text { Purine } \\
\text { (pH } 4.6 \text { acetate) }\end{array}$ & $0.04-0.99$ & $0 \cdot 026$ & $\begin{array}{c}0.57-17 \cdot 2^{* *} \\
(1.64-33 \cdot 3 \dagger \dagger\end{array}$ & $\begin{array}{l}3 \cdot 3 \pm 0 \cdot 4 \\
7 \cdot 3 \pm 0 \cdot 8) \S\end{array}$ \\
\hline & & & & $0 \cdot 26$ & $\begin{array}{l}2 \cdot 5-52 \cdot 5^{* *} \\
(5 \cdot 2-83+\dagger\end{array}$ & $\begin{array}{c}10 \cdot 8 \pm 1 \cdot 1 \\
26+17)\end{array}$ \\
\hline & & & $0.047-0.93$ & 0.60 & $\begin{array}{l}5 \cdot 3-63 \cdot 5 * * \\
(8 \cdot 9-100+\dagger\end{array}$ & $\begin{array}{r}14.9 \pm 1.0 \S \\
38 \pm 21)\end{array}$ \\
\hline & $5 \cdot 33$ & Adenine & $0 \cdot 10-1 \cdot 00$ & 0.026 & $7 \cdot 2-46 \cdot 5$ & $10.2 \pm 0.989$ \\
\hline & $5 \cdot 33$ & Adenine & $0.10-0.98$ & $\begin{array}{l}0 \cdot 26 \\
0 \cdot 026\end{array}$ & $9 \cdot 2-52$ & $11.3 \perp 0.8 \S$ \\
\hline & & (pH 4.6 acetate) & & 0.26 & $25-141$ & $30 \cdot 1 \pm 1 \cdot 6 \S$ \\
\hline \multirow[t]{11}{*}{ PGE } & $11 \cdot 4$ & Pyrimidine & $0 \cdot 115-1 \cdot 15$ & 0.06 & $2 \cdot 8-25$ & $2 \cdot 0 \pm 0 \cdot 1$ \\
\hline & & (pH 1.0 chloride) & $0 \cdot 34-1 \cdot 15$ & 0.60 & $16-47$ & $4.5 \pm 0.8$ \\
\hline & \multirow{3}{*}{$\begin{array}{l}11 \cdot 4 \\
11 \cdot 4\end{array}$} & Cytosine & \multicolumn{4}{|c|}{ Neither oxidized nor reduced } \\
\hline & & $\begin{array}{l}\text { Purine } \\
\text { (pH } 4.6 \text { acetate) }\end{array}$ & \multirow[t]{2}{*}{$0.04-0.99$} & 0.06 & $\begin{array}{r}3 \cdot 2-39 \\
(2 \cdot 1-15\end{array}$ & $\begin{array}{l}7 \cdot 0-3 \cdot 49 \\
4 \cdot 7-1 \cdot 3) \pm \ddagger\end{array}$ \\
\hline & & & & $0 \cdot 60$ & $\begin{array}{c}19-128 \\
(17-48\end{array}$ & $\begin{array}{l}42-119 \\
38-4)\end{array}$ \\
\hline & \multirow{3}{*}{$\begin{array}{r}11 \cdot 4 \\
4 \cdot 2\end{array}$} & & \multirow[t]{3}{*}{$0.05-0.93$} & $0 \cdot 26$ & $5-18$ & $23-5 \uparrow$ \\
\hline & & & & & $(3-6$ & 14-2) ๆ \\
\hline & & & & 0.60 & $5-31$ & $25-8 \pi$ \\
\hline & $4 \cdot 2$ & & & & $(2-11$ & $11-3) \pi$ \\
\hline & \multirow[t]{2}{*}{$11 \cdot 4$} & Adenine & \multirow[t]{2}{*}{$0 \cdot 10-0 \cdot 96$} & 0.06 & $12-107$ & $11 \cdot 9-9 \cdot 3$ \\
\hline & & (pH 4.6 acetate) & & $0 \cdot 60$ & $72-336$ & $66-31$ ा \\
\hline
\end{tabular}

* Five concentrations in each range; four in a very few cases.

$\dagger$ Each average current was the mcan of 3 replicate measurements on the same solution.

$¥$ Either the range of extreme values or the mean and standard deviation.

$\S$ One current omitted because deviant, probably owing to larger than usual variation in area of HMDE.

T The ratio of $i_{\mathrm{p}} / A C$ decreased with increasing concentration.

** Peak I.

†† Peak I + peak II.

$\$ \$$ Anodic peak.

At a scan rate of $36 \mathrm{~V} / \mathrm{sec}$, a very small anodic peak was observed after both cathodic peaks had been scanned; it did not appear if only cathodic peak I was scanned. This peak is probably due to oxidation of a small portion of the peak II reduction product; the size of the peak and the necessity for very fast scan rates indicate the instability of the peak II product.

Purine at PGE. On starting at zero and scanning initially toward negative potential, a single reduction peak appears at more negative potential than peak I at the HMDE; above $\mathrm{pH} 9$, the peak disappears behind background discharge. On the return scan (towards positive potential), a well-formed oxidation peak appears at much more positive potential; this peak does not appear if the initial scan at a clean electrode is toward positive potential, i.e., it is necessary to scan to potentials sufficiently negative to produce the reduction peak before the oxidation peak appears (Fig. 1). Above $\mathrm{pH} 9$, where the reduction peak is masked by background discharge, the oxidation peak is still observed provided that the initial scan is continued some distance beyond the background discharge potential. The anodic peak appears over the whole $\mathrm{pH}$ range investigated (1-12). Hence, the anodic peak is due to the oxidation of the reduction product or some species derived from it.

At both scan rates, $E_{\mathrm{p}}$ for both the anodic and cathodic peaks varies linearly with $\mathrm{pH}$ (Table $\mathrm{I}$; the peak currents are constant at each scan rate. At $0.06 \mathrm{~V} / \mathrm{sec}$ scan, the anodic peak is about one-third 
the height of the cathodic peak; at $0.6 \mathrm{~V} / \mathrm{sec}$ it is much closer in height to the cathodic peak. Above $\mathrm{pH} 9$, when the cathodic peak presumably occurs at more negative potential than background discharge, the observed anodic $i_{\mathrm{p}}$ decreases only slightly. At $\mathrm{pH} 4.6 i_{\mathrm{p}}$ for both peaks increases linearly with concentration (Table II) at $0.06 \mathrm{~V} / \mathrm{sec}$, although there is a marked decrease in the $i_{\mathrm{p}} / A C$ ratio. The latter effect is so pronounced at $0.26 \mathrm{~V} / \mathrm{sec}$ that the $i_{\mathrm{p}}-C$ plot is exponential with $i_{\mathrm{p}}$ approaching a limiting value at $1 \mathrm{~m} M$ level (Fig. 2).

Such behaviour is evidence for adsorption of either purine or its reduction product, although at high scan rates current-limiting effects due to a slow chemical process, $e . g$., structural rearrangement, or to diffusion-layer limitations may be contributory factors. Additional evidence for adsorption at the PGE is provided by the somewhat more negative potentials of the reduction peak at the PGE compared to peak I at the HMDE, assuming that the potential of zero charge on both electrodes is the same.

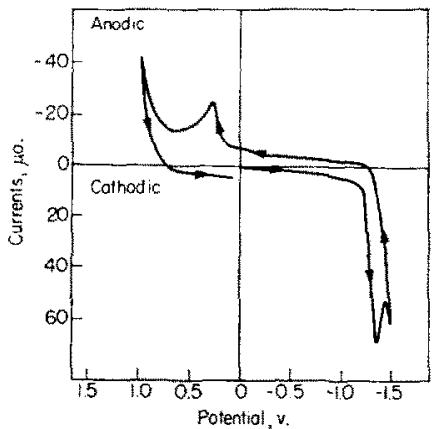

Fig. 1.-Cyclic voltammogran at PGE of $1 \mathrm{~m} M$ purine in $\mathrm{pH} 7.0$ Mcllvaine buffer. Scan-rate $0.06 \mathrm{~V} / \mathrm{sec}$. Scan started at $0.0 \mathrm{~V}$ and run toward negative potential.

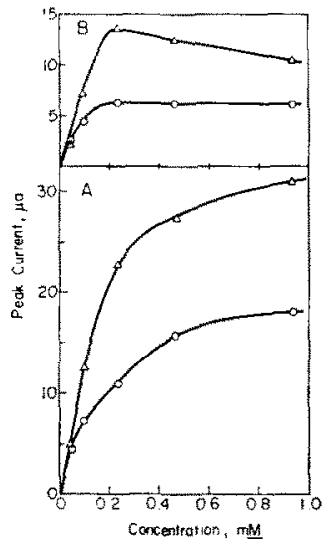

Fig. 2.-Variation of peak current with concentration on cyclic voltammetry of purine in $\mathrm{pH} 4.6$ acetate buffer at a 2 -mm PGE. $A$ : reduction peak; $B$ : oxidation peak. Scan-rates: circles, $0.26 \mathrm{~V} / \mathrm{sec}$; triangles, $0.6 \mathrm{~V} / \mathrm{sec}$.

Adenine at HMDE. Adenine shows a single cathodic peak and no anodic activity even at a 45 $\mathrm{V} / \mathrm{sec}$ scan rate. Between $\mathrm{pH} 1$ and $5 \cdot 6, E_{\mathrm{p}}$ varies linearly with $\mathrm{pH}$ at both scan rates (Table 1 ); $i_{\mathrm{p}}$ is constant to $\mathrm{pH} 5.5$ and then decreases very rapidly to vanish above $\mathrm{pH} 6$.

At $\mathrm{pH} 4.6$ (acetate), $i_{\mathrm{p}}-C$ plots are linear at both scan rates but the $i_{\mathrm{p}} / C$ ratio decreases with increasing concentration. The same general effects are noted with $\mathrm{pH} 5$ Mcllvaine buffer, although $i_{\mathrm{p}}$ is generally slightly lower than in acetate medium (Table In).

Adenine at $P G E$. Adenine shows no cathodic activity over the available potential range from $\mathrm{pH} 1$ to 12. However, a large anodic peak appears between $\mathrm{pH} 3.6$ and 10 , and is often very poorly formed at the concentration studied $(\mathrm{ca} .1 \mathrm{~m} M) ; E_{\mathrm{p}}$ varies linearly with $\mathrm{pH}$ (Table I). The $i_{\mathrm{p}}$ is approximately constant over the $\mathrm{pH}$ range. At $\mathrm{pH} 4 \cdot 6$, deviation from a linear $i_{\mathrm{p}}-C$ relation occurs at both scan rates (Table II); an exponential-type curve is produced at the faster scan rate.

As a qualitative test for adsorption of adenine at the PGE, a clean resurfaced electrode was immersed in a $0.02 \mathrm{mM}$ adenine solution for periods of 1-60 min, washed with water without the stream of water striking the surface directly, and then immersed in a previously deaerated $\mathrm{pH} 4 \cdot 7$ acetate solution; scanning between 0 and $1.3 \mathrm{~V}$, gave a well-formed anodic peak at about $1.06 \mathrm{~V}$.

\section{Polarographic behaviour}

The polarographic behaviour of pyrimidine, cytosine. purine and adenine at the DME was generally in conformity with past reports. ${ }^{8-10}$

Polarography of purine. In view of the reduction of purine at the HMDE at $\mathrm{pH} \geq 6$, contrary to a previous report, ${ }^{9}$ polarographic data for the $\mathrm{pH}$ range $1-9$ are presented (Table III).

The relatively large magnitude of wave II compared to wave $I$ is associated with the concomitant hydrogen reduction, which is catalysed by the fully reduced form of purine. ${ }^{*}$

$E_{1 / 2}$ data for purine fit the linear equations for the variation of $E_{1 / 2}$ with $\mathrm{pH}$ in acidic media.? 
TABLe III.-Polarographic behaviour of PURINE AT THE DME

\begin{tabular}{|c|c|c|c|c|c|c|}
\hline \multirow{2}{*}{ pH } & \multicolumn{3}{|c|}{ Wave I } & \multicolumn{3}{|c|}{ Wave II } \\
\hline & $\begin{array}{c}-E_{1 / 2}, \\
V\end{array}$ & $\begin{array}{l}i_{1}, \\
\mu A\end{array}$ & $i_{1} / C$ & $\begin{array}{c}-E_{1 / 2} \\
V\end{array}$ & $\begin{array}{l}i_{1} \\
\mu A\end{array}$ & $i_{1} / C$ \\
\hline 1.0 & 0.73 & $7 \cdot 1$ & $7 \cdot 8$ & 1.00 & $11 \cdot 3^{*}$ & $12 \cdot 4$ \\
\hline $2 \cdot 0$ & 0.83 & 6.9 & $7 \cdot 6$ & 1.08 & $11.8 *$ & 12.9 \\
\hline $3 \cdot 0$ & 0.95 & $6 \cdot 8$ & $7 \cdot 5$ & & & \\
\hline 3.7 & 1.02 & 6.0 & $6 \cdot 6$ & 1.25 & 12.7 & 13.9 \\
\hline 5.7 & $1 \cdot 19$ & $5 \cdot 8$ & $6 \cdot 4$ & 1.39 & $19 \cdot 3$ & $21 \cdot 2$ \\
\hline 7.0 & 1.29 & $7 \cdot 0$ & $7 \cdot 7$ & 1.46 & $17 \cdot 0^{*}$ & $18 \cdot \overline{7}$ \\
\hline 7.6 & 1.32 & 6.0 & $6 \cdot 6$ & 1.49 & $9 \cdot 8$ & 10.8 \\
\hline 7.8 & $1 \cdot 35$ & 5.8 & $6 \cdot 4$ & 1.52 & $7 \cdot 7$ & 8.5 \\
\hline 8.0 & 1.38 & 7.8 & $8 \cdot 6$ & 1.55 & $8 \cdot 4$ & $9 \cdot 2$ \\
\hline $9 \cdot 0$ & 1.46 & $8 \cdot 1$ & 8.9 & 1.58 & $6 \cdot 6$ & $7 \cdot 3$ \\
\hline
\end{tabular}

* Maxima occurred on wave.

$\dagger$ Very poorly defined wave; difficult to measure $E_{1 / 2}$ and $i_{1}$ accurately.

\section{Electrocapillary behaviour}

Cyclic voltammetry at mercury and, more particularly, at graphite electrodes suggests that adsorption of purines and possibly pyrimidines, as well as of intermediates and/or products, might be a significant factor in the electrochemical reactions.

At $\mathrm{pH} 4 \cdot 6$, electrocapillary studies show that purine, adenine and cytosine are adsorbed at mercury, since solutions of each produce a depression in the electrocapillary curve, compared to that obtained for background alone, in the region of the electrocapillary maximum $(\mathrm{ecm})$, which would indicate that the adsorbed species are probably uncharged (Fig. 3). The order of electrocapillary depression is: adenine $>$ purine $>$ cytosine.

Owing to erratic drop-times, caused by vibration in the work area, it was difficult to observe clearly the electrocapillary behaviour at potentials more negative than -1.2 to $-1.4 \mathrm{~V}$, the region of greatest interest, since faradaic activity frequently occurred at these or more negative potentials. The compounds were, therefore, examined at the DME by alternating current polarography.

\section{Alternating current polarographic behaviour}

Pyrimidine. Between pH 1 and 5, pyrimidine shows a single well formed a.c. peak (I, Fig. 4A), with a summit potential, $E_{\mathrm{s}}$, which varies linearly with $\mathrm{pH}$ (Table IV) with a change in slope at $c a$. $\mathrm{pH}$ 5, which accounts for its designation as peaks I and II. The separation from background discharge is sufficient for accurate measurement of $i_{\mathrm{p}}$, which has a minimum value at $\mathrm{pH} 3.0$ (Table V). An additional small, very poorly formed peak may be seen at $\mathrm{pH} 3.0\left(E_{\mathrm{s}}=1.04 \mathrm{~V}\right)$. At $\mathrm{pH} 3.7, i_{\mathrm{p}}$ varies lincarly with concentration (Table VI).

Between $\mathrm{pH} 1$ and 7 , the presence of pyrimidine shifts the background discharge to more positive potential. At $\mathrm{pH} 7 \cdot 0$, an inflection was noted on the background discharge, which resolved itself into a very well formed peak at pH 7.8 (III, Fig. 4B). Above pH 10-11, no peaks are observed. Over the $\mathrm{pH}$ range 1-10, pyrimidine shows no tendency to depress or elevate the base current.

Subsequent work by $O^{\prime} R e i l l{ }^{13}$ has shown that two additional small a.c. peaks can be observed. Between $\mathrm{pH} 3$ and 4 , a very small $\mathrm{pH}$ independent peak $\left(E_{\mathrm{s}}=-1.25 \mathrm{~V}\right)$ is observed. At $\mathrm{pH}$ values above 10.6, a fifth peak is seen as a slight inflection on the background discharge.

Clearly, the three peaks observed in the present study correspond to waves I, III and IV observed on DME polarography by Smith and Elving. ${ }^{9}$ The two less distinct waves observed by O'Reilly ${ }^{13}$ correspond to DME waves II and V.9

Cytosine. Cytosine shows a single small a.c. peak, with $E_{8}$ varying linearly with $\mathrm{pH}$ (Table IV); $i_{\mathrm{p}} / A C$ is constant at $\mathrm{pH} 4 \cdot 6$, (Table II). The peak currents are much smaller than those for purine and adenine. Between $25^{\circ}$ and $40^{\circ}$ the temperature-dependence of $i_{\mathrm{p}}$ is high $(3.2 \% / \mathrm{deg})$.

Purine. Two reduction peaks appear in the potential range from 0.0 to $-1.8 \mathrm{~V}$ (Fig. 5). At $\mathrm{pH} 1$ to 2, a very large maximum appears on peak II, similar to that observed on d.c. polarography; at higher $\mathrm{pH}$, the maximum disappears and peak $\Pi$ is about half the height of peak I but considerably broader.

Both peaks show a linear pH-dependence of $E_{\mathrm{s}}$ between $\mathrm{pH} 1$ and 6 (Table IV), and a linear $i_{\mathrm{p}}-C$ relation at $\mathrm{pH} 4 \cdot 6$. Between $25^{\circ}$ and $40^{\circ}$, the temperature-dependence of both peak heights is high $(1.2 \% / \mathrm{deg}$ for $\mathrm{I} ; 1.4 \% / \mathrm{deg}$ for II). 


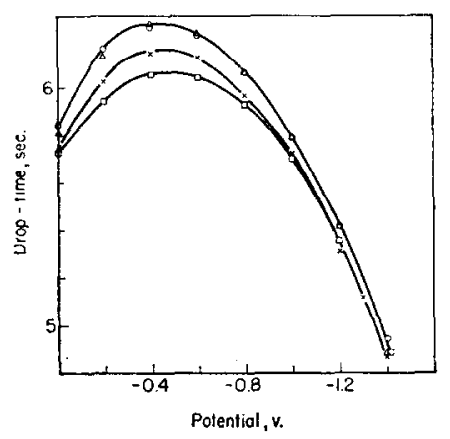

FIG. 3.-Electrocapillary curves for $2.5 \mathrm{~m} M$ cytosine (triangles), purine (crosses) and adenine (rectangles) in $\mathrm{pH} 4.6$ acetate buffer (background alone: circles).

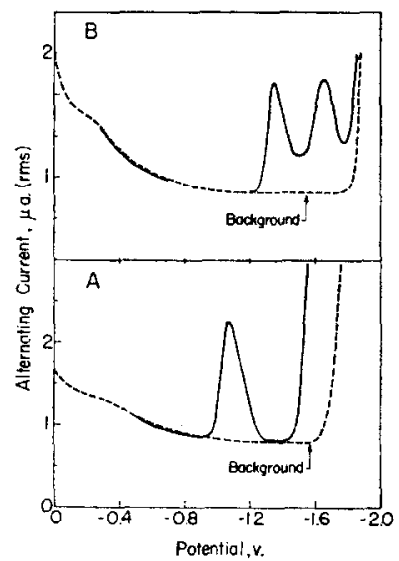

Fig. 4.-Alternating current polarogram of $2 \mathrm{~m} M$ pyrimidine. $A: \mathrm{pH} 4.6$ acetate buffer; $B: \mathrm{pH} 7.8$ McIlvaine buffer. Where only the background trace is shown, that of the test solution merged with it.

TABLe IV.-LINEAR $E_{\mathrm{s}} v s$. pH RELATIONSHIPS FOR PURINe, ADENINe, PYRIMIDINE AND CYTOSINE ON ALTERNATING CURRENT POLAROGRAPHY

\begin{tabular}{lcclc}
\hline Compound & $\begin{array}{c}\text { Concn., } \\
m \mathrm{M}\end{array}$ & pH Range & Wave & $\begin{array}{c}E_{\mathrm{g}}, \\
V\end{array}$ \\
\hline Pyrimidine* & 2.29 & $1-5$ & I & $-0.58-0.108 \mathrm{pH}$ \\
& & $5-9$ & II & $-0.85-0.064 \mathrm{pH}$ \\
Cytosine & 0.99 & $7-9$ & III & $-2.01+0.036 \mathrm{pH}$ \\
Purine & 0.96 & $1-6$ & & $-1.27-0.054 \mathrm{pH}$ \\
& & $1-6$ & I & $-0.72-0.080 \mathrm{pH}$ \\
Adenine & 0.98 & $1-6$ & II & $-1.11-0.041 \mathrm{pH}$ \\
\end{tabular}

* Two other a.c. waves have been reported for pyrimidine ( $c f$. text).

TABLE V.-EFFECT OF pH ON a.c. SUMMIT POTENTIAL AND CURRENT FOR $2 \mathrm{~m} M$ PYRIMIDINE

\begin{tabular}{|c|c|c|c|c|}
\hline \multirow{2}{*}{ Buffer* } & \multirow{2}{*}{$\mathrm{pH}$} & \multicolumn{2}{|c|}{$E_{6}$ for peak, $V$} & \multirow{2}{*}{$\begin{array}{c}\text { First } \\
\text { peakt } \\
\Delta i_{\mathrm{s}} \\
\mu A\end{array}$} \\
\hline & & First $\dagger$ & Second $\ddagger$ & \\
\hline Chloride & 1.05 & -0.680 & & $1 \cdot 76$ \\
\hline Chloride & 2.00 & -0.765 & & $1 \cdot 62$ \\
\hline Chloride & 2.95 & -0.870 & & $0 \cdot 67$ \\
\hline Acetate & 3.65 & -0.975 & & $1 \cdot 18$ \\
\hline Acetate & 4.65 & $-1 \cdot 070$ & & 1.45 \\
\hline Acetate & $5 \cdot 55$ & $-1 \cdot 210$ & & $2 \cdot 03$ \\
\hline Mcllvaine & $7 \cdot 0$ & -1.310 & $-1 \cdot 700$ & $2 \cdot 38$ \\
\hline McIlvaine & $7 \cdot 82$ & -1.355 & -1.665 & $1 \cdot 31$ \\
\hline Ammonia & $9 \cdot 1$ & -1.440 & -1.860 & 1.47 \\
\hline
\end{tabular}

* Ionic strength $0.5 \mathrm{M}$.

† The first peak to appear on the polarogram (peak I between $\mathrm{pH} 1$ and 4.7, and pcak II between pH 5.6 and 9.1).

$\ddagger$ The second peak to appear on the polarogram (peak III). 
TABle VI.-VARIATION OF PEAK CURRENT WTTH CONCENTRATION FOR VARIOUS PURINES AND PYRIMIDINES ON a.c. POLAROGRAPHY

\begin{tabular}{|c|c|c|c|c|c|}
\hline Compound & $\begin{array}{c}\text { Concn. } \\
\text { range, } \\
m \mathrm{M}\end{array}$ & $\begin{array}{l}\text { No. of } \\
\text { concns. }\end{array}$ & $\mathrm{pH}^{*}$ & $\begin{array}{c}i_{\mathrm{p}}^{\dagger} \\
\text { range }\end{array}$ & $i_{\mathrm{p}} / C \ddagger$ \\
\hline Pyrimidine§ & $1 \cdot 2-3 \cdot 1$ & 3 & $3 \cdot 7$ & $0 \cdot 4-1 \cdot 2$ & $0.367 \pm 0.015$ \\
\hline Cytosine & $0 \cdot 5-2 \cdot 5$ & 4 & $4 \cdot 7$ & $0 \cdot 1-1 \cdot 4$ & $0.46 \pm 0.13$ \\
\hline Purine & $0 \cdot 5-2 \cdot 4$ & 4 & $4 \cdot 7$ & $\begin{array}{r}\text { I } 0 \cdot 3-2 \cdot 3 \\
\text { II } 0 \cdot 2-1 \cdot 1\end{array}$ & $\begin{array}{l}0.82 \pm 0.16 \\
0.41 \pm 0.05\end{array}$ \\
\hline $\begin{array}{l}\text { Adenine } \\
\text { 2-Amino- }\end{array}$ & $0 \cdot 3-2 \cdot 4$ & 5 & $4 \cdot 7$ & $0 \cdot 3-2 \cdot 5$ & $1 \cdot 16 \pm 0 \cdot 15$ \\
\hline pyrimidine & $1 \cdot 0-2 \cdot 4$ & 3 & $3 \cdot 7$ & $0.3-0.9$ & $0.35 \pm 0.04$ \\
\hline $\begin{array}{l}\text { pyrimidine } \\
\text { pyyaros }\end{array}$ & $1 \cdot 0-2 \cdot 5$ & 3 & $4 \cdot 7$ & $0.1-0.4$ & $0.15 \pm 0.03$ \\
\hline
\end{tabular}

* Acetate buffer, ionic strength $0.5 \mathrm{M}$.

$\dagger$ This peak current is the root mean square value of the a.c. summit current, $\Delta i_{\mathrm{s}}$.

$\$$ Mean and standard deviation.

\& Capillary characteristics: $h 605 \mathrm{~mm}, m 0.89 \mathrm{mg} / \mathrm{sec}$ for pyrimidine; $h 615 \mathrm{~mm}, m 1.05 \mathrm{mg} / \mathrm{sec}$ for the others.

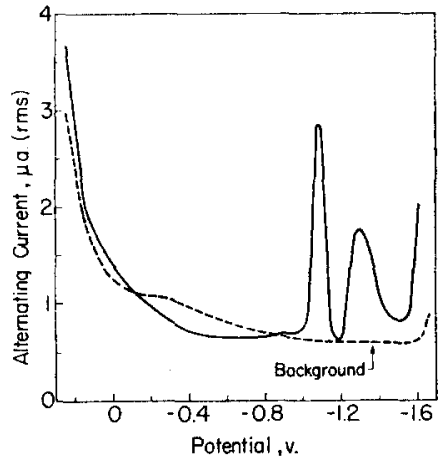

Fig. 5.-Alternating current polarogram of $2 \mathrm{~m} M$ purine in $\mathrm{pH} 4.6$ acetate buffer.

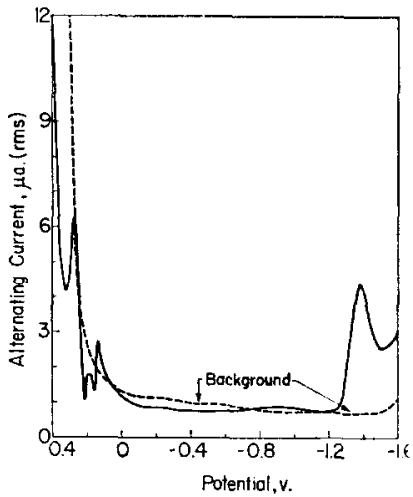

Fig. 6.-Alternating current polarogram of $2 \mathrm{~m} M$ adenine in $\mathrm{pH} 4 \cdot 7$ acetate buffer.

Purinc depresses the basc current in the rcgion of the ecm (Table VII; Fig. 5), although the effect is less than that for adenine. The extent of the depression increases with increasing $\mathrm{pH}$ at the values studied (1.05, 4.6 and 5.6). A slight elevation of the base current occurs at potentials immediately before the appearance of peak I. Base current depression and elevation are less at $40^{\circ}$.

With increasing $\mathrm{pH}$, the background discharge in the presence of purine shifts to more positive potential.

Adenine. Over the potential range from 0.40 to $-1.80 \mathrm{~V}$, usually only a single well formed a.c. peak is observed (Table IV). At concentrations above about $0.5 \mathrm{~m} M$, two or, occasionally, three additional very closely spaced peaks appear at much less negative potential $e . g ., \sim 0.27,0.19$ and $0 \cdot 13 \mathrm{~V}$ at $\mathrm{pH} 4.7$ (Fig. 6).

Between $\mathrm{pH} 1$ and $6, E_{\mathrm{s}}$ of the faradaic peak at negative potential varies linearly with $\mathrm{pH}$ (Table IV). At low $\mathrm{pH}(1-2) i_{\mathrm{p}}$ is much greater than at higher $\mathrm{pH}, e . g ., 6.8 \mu \mathrm{A}$ at $\mathrm{pH} 1$ and $1.4 \mu \mathrm{A}$ at $\mathrm{pH} 4.7$ for $1 \mathrm{~m} M$ adenine; hence, an a.c. maximum probably occurs at low $\mathrm{pH}$ in agreement with that observed in d.c. polarography. ${ }^{9}$

A small well formed reproducible a.c. peak appears after the large maximum (at $-1.30 \mathrm{~V}$ ) at $\mathrm{pH} 1.05$; its current is about the same as that for the single adenine peak observed at higher $\mathrm{pH}$.

The faradaic peak at $-1.40 \mathrm{~V}$ in $\mathrm{pH} 4.6$ acetate buffer shows a more or less constant $i_{\mathrm{p}} / C$ ratio (Table VI). The heights of the closely spaced peaks at more positive potential are variable and show no simple concentration dependence.

In the presence of adenine, the base current is depressed between 0.4 and $0.27 \mathrm{~V}$ to about a quarter of its magnitude in the absence of adenine; $i-t$ curves in this region reveal that the a.c. current in the 
TABLE VII.--EFFECT OF PURINE, ADENINE, PYRIMIDINE AND CYTOSINE ON THE a.C. POLAROGRAPHIC BASE CURRENT DEPRESSION AND ELEVATION

\begin{tabular}{|c|c|c|c|c|}
\hline Compound & Buffer & $\mathrm{pH}$ & $\begin{array}{c}\text { Depression, } \\
\text { potential range } \\
V\end{array}$ & $\begin{array}{c}\text { Elevation, } \\
\text { potential range } \\
V\end{array}$ \\
\hline \multirow[t]{3}{*}{ Cytosine } & Chloride & $1 \cdot 05$ & $0.28-0.55$ & very small \\
\hline & Acetate & $4 \cdot 6$ & $0.18-1.09$ & very small \\
\hline & Acetate & $5 \cdot 6$ & $0 \cdot 10-0.75$ & $0.75-1.47$ \\
\hline \multirow{3}{*}{ Purine } & Chloride & 1.05 & $0 \cdot 10-0.34$ & $0.34-0.85$ \\
\hline & Acetate & $4 \cdot 6$ & $0.10-0.83$ & about 0.9 \\
\hline & Acetate & $5 \cdot 6$ & $0.10-0.80$ & about 1.0 \\
\hline \multirow[t]{5}{*}{ Adenine } & Chloride & 1.05 & $0.25-0.69$ & $0.69-0.89$ \\
\hline & Chloride & 2.03 & $0.24-0.68$ & very small \\
\hline & Acetate & 3.6 & $0.00-0.75$ & $0.85-1.20$ \\
\hline & Acetate & $4 \cdot 6$ & $0.05-0.83$ & $0.83-1.25$ \\
\hline & Acetate & $5 \cdot 6$ & $0.00-0.75$ & $0.75-1.35$ \\
\hline
\end{tabular}

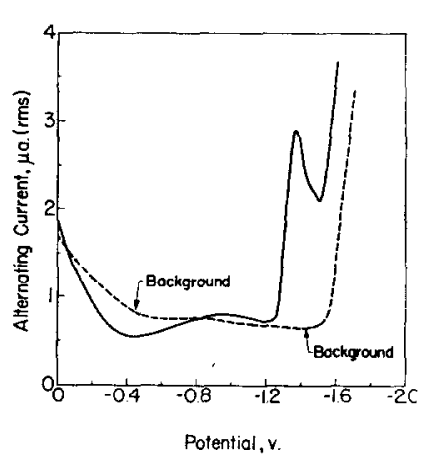

Fig. 7.-Alternating current polarogram of $2 \mathrm{~m} M$ adenosine in $\mathrm{pH} 3 \cdot 6$ acetate buffer.

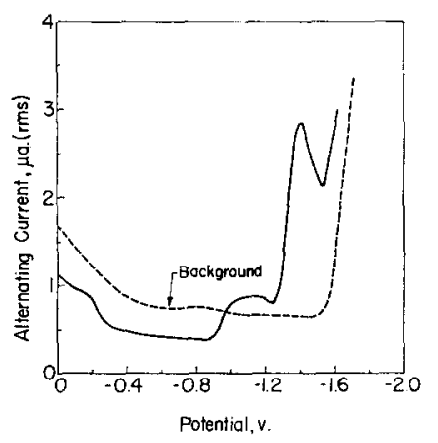

Fig. 8.-Alternating current polarogram of $2 \mathrm{mM}$ adenosine monophosphate in $\mathrm{pH} 3.7$ acetate buffer.

presence of adenine is not proportional to $t^{2 / 3}$ as theoretically predicted for a diffusion controlled process but, after initial growth, becomes almost constant. At the first peak, a.c. $i-t$ curves are normal and the current is unchanged by the presence of adenine. Between 0.27 and $0.24 \mathrm{~V}$, a.c. polarograms of adenine and of background alone coincide. A depression occurs at $0.21 \mathrm{~V}$ with a small peak at $0 \cdot 20-0.18 \mathrm{~V} ; i-t$ curves in this potential range show an initial increase in current followed by a decrease; in the absence of adenine, normal curves are observed. If a capillary with a long drop-time is used in the region of $0.2 \mathrm{~V}$, the decrease of current with time is very pronounced.

Adenine markedly depresses the base current in the ecm region (Table IX) in all of the background solutions employed; the effect is least pronounced at $\mathrm{pH} 3.6$. At potentials more negative than that of the ecm, a region of base current elevation usually appears (Table VII; Fig. 6).

Below $\mathrm{pH} 3.7$, the presence of adenine appears to have only slight, if any, effect on the background discharge potential. At $\mathrm{pH} 4 \cdot 7$ and 5.7, adenine causes an appreciable shift of background discharge to more positive potential.

Related compounds. In order better to identify the chemical structures involved in adsorption as well as for general orientative purposes, selected purines and pyrimidines were examined, especially with regard to their effect on the base current, i.e., adsorption behaviour. Generally, each compound was investigated at only a single $\mathrm{pH}$, where the d.c. polarographic behaviour was well known.

2-Aminopyrimidine gives a single small a.c. peak at $-0.91 \mathrm{~V}$ at $\mathrm{pH} 3.6$, with height linearly dependent on concentration (Table VI). No noticeable effects on the base current or discharge potential are evident.

2-Hydroxypyrimidine gives one small a.c. peak at $-0.91 \mathrm{~V}$ at $\mathrm{pH} 4.7$; the current, which is linearly dependent on concentration (Table VI), is the smallest for any compound examined. No appreciable effect on base current or onset of background discharge is observed.

At $\mathrm{pH} 3 \cdot 6$, adenosine gives a single a.c. peak at $-1.37 \mathrm{~V}$, which is slightly smaller than that observed for adenine at the same $\mathrm{pH}$ (at the $2.0 \mathrm{mM}$ level, $i_{\mathrm{p}}$ is $2.12 \mu \mathrm{A}$ for adenine and $1.74 \mu \mathrm{A}$ for 
adenosine), Fig. 7; the background discharge is shifted about $100 \mathrm{mV}$ more positive. In the region of the ecm, adenosine produces a large base current depression with a maximum effect at $-0.4 \mathrm{~V}$. At about $-1.0 \mathrm{~V}$ the base current is elevated.

Adenosine monophosphate gives a single a.c. peak at $-1 \cdot 40 \mathrm{~V}$ at $\mathrm{pH} 3 \cdot 6$, close to the background discharge which is itself shifted to more positive potential (Fig. 8). A very large base current depression occurs between 0 and $-0.9 \mathrm{~V}$, which would clearly have continued to positive potentials. A large base current elevation occurs between -1.00 and $-1.25 \mathrm{~V}$.

Comparative behaviour. In summary, with increasing substitution of adenine at $N-9, i_{\mathrm{p}}$ decreases appreciably and $E_{\mathrm{B}}$ becomes slightly more negative (Table VIII).

Comparative results obtained under identical concentration, capillary and a.c. conditions, are summarized in Table IX. The pH values selected were those for which the d.c. polarographic processes are well documented and a good estimate of the number of electrons involved in the process

TABLE VIII.-ALTERNATING CURRENT POLAROGRAPHIC CHARACTERISTICS OF ADENINE AND DERIVATIVES IN $\mathrm{pH}$ 3.6 ACETATE MEDIUM

\begin{tabular}{lccc} 
Compound & $\begin{array}{c}\text { Concn., } \\
m \mathrm{M}\end{array}$ & $\begin{array}{c}E_{\mathrm{s}}, \\
V\end{array}$ & $\begin{array}{c}\Delta i_{\mathrm{s}}, \\
\mu A\end{array}$ \\
\hline Adenine & 2.0 & 1.380 & 2.12 \\
Adenosine & 2.0 & 1.370 & 1.74 \\
Adenosine monophospate & 2.0 & 1.400 & 1.51 \\
Adenosine triphosphate & 2.0 & 1.420 & 0.85 \\
\hline
\end{tabular}

* Capillary characteristics: $h 700 \mathrm{~mm} ; m 1.086 \mathrm{mg} / \mathrm{sec}$.

TABLE IX.-COMPARISON OF a.c. POLAROGRAPHY AND LEMO VALUES FOR VARIOUS PURINES AND PYRIMIDINES

\begin{tabular}{|c|c|c|c|c|c|c|}
\hline \multirow{2}{*}{ Compound* } & \multirow{2}{*}{$\mathrm{pH}$} & \multicolumn{2}{|c|}{ Reversibility factor $\uparrow$} & \multirow{2}{*}{$\begin{array}{c}\text { LEMO } \ddagger \\
\text { energy } \\
\text { coeff. } k_{i}\end{array}$} & \multicolumn{2}{|c|}{$-E_{1 / 2}, V \S$} \\
\hline & & $n=1$ & $n=2$ & & $\mathrm{pH} 0$ & $\mathrm{pH} 5 \cdot 7$ \\
\hline 2-Hydroxypyrimidine & $\begin{array}{l}4 \cdot 08 \\
4 \cdot 87 \\
5 \cdot 60\end{array}$ & $\begin{array}{l}11 \cdot 7 \\
12 \cdot 4 \\
16 \cdot 2\end{array}$ & & -0.670 & 0.530 & 0.975 \\
\hline Purine(I) & $\begin{array}{l}4 \cdot 08 \\
4 \cdot 87 \\
5 \cdot 60\end{array}$ & $\begin{array}{l}34 \cdot 4 \\
37 \cdot 8 \\
36 \cdot 1\end{array}$ & $\begin{array}{l}8 \cdot 6 \\
9 \cdot 4 \\
9 \cdot 0\end{array}$ & -0.739 & 0.697 & $1 \cdot 170$ \\
\hline Purine(II) & $\begin{array}{l}4 \cdot 08 \\
4 \cdot 87 \\
5 \cdot 60\end{array}$ & $\begin{array}{l}16 \cdot 5 \\
25 \cdot 6 \\
20 \cdot 5\end{array}$ & $\begin{array}{l}4 \cdot 1 \\
6 \cdot 4 \\
5 \cdot 1\end{array}$ & & 0.902 & 1.358 \\
\hline Cytosine & $\begin{array}{l}4.08 \\
4.87 \\
5.60\end{array}$ & $\begin{array}{l}27 \cdot 1 \\
28 \cdot 0 \\
36 \cdot 3\end{array}$ & $\begin{array}{l}6 \cdot 8 \\
6 \cdot 9 \\
9 \cdot 1\end{array}$ & -0.795 & $1 \cdot 125$ & $1 \cdot 540$ \\
\hline Pyrimidine & $\begin{array}{l}4 \cdot 08 \\
4.87 \\
5 \cdot 60\end{array}$ & $\begin{array}{l}20 \cdot 7 \\
24 \cdot 1 \\
34 \cdot 2\end{array}$ & & -0.820 & 0.576 & $1 \cdot 175$ \\
\hline 2-Aminopyrimidine & $\begin{array}{l}4 \cdot 08 \\
4 \cdot 87 \\
5 \cdot 60\end{array}$ & $\begin{array}{l}18 \cdot 8 \\
20 \cdot 7 \\
21 \cdot 4\end{array}$ & & -0.820 & 0.685 & $1 \cdot 115$ \\
\hline Adenine & $\begin{array}{l}4.08 \\
4.87 \\
5.60\end{array}$ & $\begin{array}{l}53 \cdot 5 \\
54 \cdot 1 \\
30 \cdot 4\end{array}$ & $\begin{array}{r}13 \cdot 9 \\
14 \cdot 0 \\
7.9\end{array}$ & -0.865 & 0.975 & $1 \cdot 488$ \\
\hline
\end{tabular}

* All compounds were examined at the $2 \mathrm{~m} M$ concentration level. The numerals refer to the two purine waves.

$\dagger$ Method of calculation is described in the text.

$\$$ Taken from reference 6 except for the values for 2-hydroxy-and 2-aminopyrimidine, which were kindly furnished by Dr. A. Pullman.

$\S$ Calculated from references 9 and 10. 
could be made. A reversibility factor was calculated at each particular $\mathrm{pH}$ studied, by using the relation

$$
\text { Reversibility factor }=\frac{\left(\Delta i_{s}\right)_{\text {expt }}}{\left(\Delta i_{s}\right)_{\text {theory }}} \times 100
$$

where $\left(\Delta i_{s}\right)_{\text {theory }}$ was calculated from the equation ${ }^{28}$

$$
\left(\Delta i_{\mathrm{B}}\right)_{\text {theory }}=\frac{n^{2} F^{2} V A \omega^{1 / 2} D_{0}^{1 / 2} C}{4 R T} \times 0.458
$$

where $n$ is the faradaic number of electrons, $F$ the Faraday, $V$ the amplitude of the applied alternating voltage, $A$ the maximum area of the mercury drop, $\omega$ the angular frequency, $D_{0}$ the diffusion coefficient of the purine or pyrimidine, $C$ the millimolar concentration of the electroactive material, $R$ the gas constant and $T$ the absolute temperature. The expression was multiplied by 0.458 to correct for the much lower current observed for the reversible Fe(III)/Fe(II) system in oxalate media; the low current observed for even such a reversible system was due to the uncompensated capillary thread resistance and other instrumental effects. For those electrochemical reductions where it was known that only a single electron was involved in the d.c. process, $\left(\Delta i_{\mathrm{s}}\right)_{\text {theory }}$ was calculated only for $n=1$ e.g., pyrimidine and 2-aminopyrimidine. Several of the d.c. processes were known to involve two or more electrons, e.g., adenine, purine and cytosine. Because of the low reversibility of these processes, it was considered highly unlikely that $n$ was greater than 2 ; indeed, it is more likely that $n$ in all cases is 1. Nevertheless, reversibility factors in the latter cases were calculated based on $n=1$ and $n=2$ (Table IX). Britz and Bauer ${ }^{30}$ have reported that although aromatic nitro compounds exhibit a single 4- or 6-electron d.c. wave, the a.c. wave corresponds to only a 1-electron process.

\section{ELECTROCHEMICAL REDOX MECHANISMS}

To facilitate detailed discussion of the electrochemical mechanistic pathways for the individual compounds, reversibility, faradaic $n$ values and adsorption phenomena, as these affect all of the compounds involved, will first be considered.

Reversibility. The a.c. polarographic current observed for the various compounds examined is much less than would be expected for even a completely reversible 1-electron process. The fairly large temperature dependence of the faradaic a.c. waves is characteristic of processes having a low degree of reversibility.

Even where cyclic voltammetry showed an anodic-cathodic wave pair, e.g., oxidation of the product produced on reduction of the original species, the separation in peak potentials was very much greater than expected for a perfectly reversible redox couple. ${ }^{14,15}$

Faradaic $\mathrm{n}$ values. In stationary clcctrode voltammetry, the peak current for an essentially irreversible electrode process at $25^{\circ}$ is defined by

$$
i_{\mathrm{p}}=3.01 \times 10^{5} n\left(\alpha n_{\mathrm{a}}\right)^{1 / 2} A D^{1 / 2} C V^{1 / 2}
$$

where $i_{\mathrm{p}}$ is in $\mu \mathrm{A}, n$ is the faradaic number of electrons transferred per molecule of reactant electrolysed, $\alpha$ is the transfer coefficient and $n_{\mathrm{a}}$ the number of electrons involved in the rate-determining step of the electrode process, $A$ is the electrode area in $\mathrm{mm}^{2}, C$ is the concentration of the electroactive species in mmole/l., $D$ is its diffusion coefficient in $\mathrm{cm}^{2}$ sec. ${ }^{-1}$ and $V$ is the scan rate in $V / \mathrm{sec}$.

The peak current should vary linearly with concentration and with the square root of scan rate. For the scan rates used in the present study at the PGE and HMDE the current ratio at each should be 0.316 ; generally, the agreement with this prediction is satisfactory.

Since $n_{\mathrm{a}}$ is generally 1 and $\alpha$ generally varies between 0.3 and 0.7 , the term $\left(\alpha n_{\mathrm{a}}\right)^{1 / 2}$ is usually between 0.55 and 0.84 . If the not unreasonable assumption is made that $\alpha$ 
would not differ by a factor of more than 1.5-2 for the different purines and pyrimidine processes observed, the faradaic $n$ values would be approximately proportional to the peak currents, or to $i_{\mathrm{p}} / A C$.

Adsorption phenomena. The a.c. results indicate that all of the purine-based compounds are adsorbed on mercury. With the exception of the phosphate derivatives, the compounds are adsorbed in the region of the electrocapillary maximum. The phosphate derivatives appear to be more strongly adsorbed at potentials positive to the ecm, which suggests adsorption of a negatively charged species formed by acidic dissociation of the phosphate grouping as, for example, with adenosine phosphates,

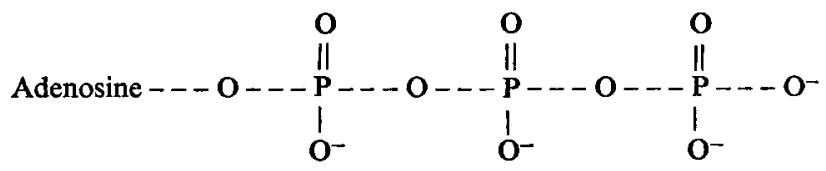

The fact that of the four pyrimidines examined only cytosine gave any evidence for adsorption at mercury, suggests that the site of adsorption of purines may be in the imidazole ring, at either position 7 or 8 , since position 9 is occupied in the adenosines. Since position 7 is occupied by a heterocyclic nitrogen atom, adsorption may be more favourable at this position. It is more likely, however, that adsorption would involve $\pi$-bonding to the aromatic ring. Base current elevation immediately before the appearance of the a.c. peak suggests that in these potential regions the species are desorbed from the electrode surface.

Vetter ${ }^{16,17}$ used a bridge and a modified tensammetric method to study the effects of purines and pyrimidines on the differential capacity of a DME in $1 M$ sodium chloride with a view to determining the relative magnitudes of various intermolecular forces. His results indicate strong intermolecular interaction of adsorbed molecules only with the usual DNA and RNA components such as adenine, guanine, thymine, cytosine and uracil. Generally, Vetterl sought pronounced depressions in the capacity curves, which only appeared at relatively high concentrations $(5 \mathrm{~m} M$ adenine or $39 \mathrm{~m} M$ cytosine). Direct comparison of the present work and that of Vetterl is difficult because of the differences in techniques and concentrations employed; however, all of the capacity curves presented by Vetterl showed base current depressions in the presence of a purine or a pyrimidine as compared to background, followed in most cases by an elevation. The failure of Vetterl to report a.c. peaks may be explained on the basis of either confusion of the faradaic current with background discharge owing to the high concentrations employed or the electrochemical inactivity of some species at $\mathrm{pH} 7$.

It was particularly noticeable in the present study that all of the adenine-based compounds are strongly adsorbed on mercury; cyclic and linear scan voltammetry indicates that purine and adenine are adsorbed on graphite. The a.c. peaks observed for adenine at the DME at positive potential suggest either that the compound is adsorbed or that a mercury-adenine compound is formed; the a.c. current-time behaviour agrees with either of these processes occurring, although, since adenine is subsequently adsorbed at potentials near that of the ecm, it is more likely that compound formation occurs. The almost constant height of the adenine peaks at positive potential and above $0.5 \mathrm{~m} M$ concentration indicates a process which is dependent 
mainly on the electrode surface area, i.e., effective saturation of the available surface is reached at $0.5 \mathrm{~m} M$.

Failure of the peaks at positive potential to appear at concentrations below $0.4 \mathrm{~m} M$ suggests their shift to more positive potential, as would be expected if adenine does react with mercury e.g., similarly to riboflavin. ${ }^{18}$ The small magnitude of the peaks and the fact that often only two, rather than three, peaks were noted complicate the interpretation. There is further evidence that the peaks are not tensammetric in nature, e.g., a marked base current depression at potentials more positive than even the most positive peak and $i-t$ curves characteristic of an adsorption process. If the peaks were in fact tensammetric, the polarogram would be expected to coincide with the background polarogram at potential more positive than that of the most positive peak.

$\Lambda$ denine possess the steric configuration necessary for metal chelation; the $N(7)$ and the extracyclic heteroatom attached to $C(6)$, provide favourable sites for formation of a five-membered ring, representing a particularly stable configuration:<smiles>[M]C1NCNc2ncnc(N)c21</smiles>

This expectation ( $c f$. pp. 253-8 of reference 6), is borne out in experiment since bivalent metals chemically related to mercury, i.e., copper, zinc and nickel, form metal complexes with purines. ${ }^{19}$ Formation constarts for the reaction of metal ions with purine and substituted purines have been reported, ${ }^{20}$ as has the reaction of mercury(II) acetate with purines, including adenine, in aqueous or acetic acid solutions. $^{21}$

Pyrimidine. No evidence for reversibility was observed at the HMDE for any of the five peaks. The close agreement between the $\mathrm{pH}$ dependences by cyclic voltammetry (Table I) and slow single scan polarography ${ }^{10}$ indicates that identical mechanisms are operative in both cases. Thus, peak I results from the 1-electron reduction of the 3,4 bond to form a free radical, which dimerizes very rapidly, as indicated by the very small peak II currents obtained on cyclic voltammetry, which are often lower than those for peak $\mathrm{I}$, or is reduced at more negative potential in a further 1-electron process (peak II) to 3,4-dihydropyrimidine. At higher $\mathrm{pH}$, the 2-electron peak III, due to combined peak I and II processes, occurs. Peak IV represents the 2-electron reduction of dihydropyrimidine to tetrahydropyrimidine. The difference in the $\mathrm{pH}$-dependence of waves III and IV results in their merging to form the 4-electron peak V.

The $i_{\mathrm{p}} / A C$ ratios for pyrimidine peaks I, III and $\mathrm{V}$ and purine peak $\mathrm{I}$ are in the ratios $1 \cdot 0: 2 \cdot 0: 3 \cdot 6: 2 \cdot 5$ at $0 \cdot 026 \mathrm{~V} / \mathrm{sec}$ and $1 \cdot 0: 1 \cdot 7: 3 \cdot 6: 2 \cdot 5$ at $0 \cdot 26 \mathrm{~V} / \mathrm{sec}$, which are in reasonable agreement for the ratio of faradaic $n$ values- $1: 2: 4: 2$.

The single cathodic peak observed for pyrimidine at the PGE over the whole $\mathrm{pH}$ range corresponds most closely to the succession of peaks I, II and possibly IV, observed at the HMDE; the lower cathodic potential range at PGE results in peaks III and V (at HMDE) not appearing. The fairly linear current-concentration relation at $\mathrm{pH} 1.05$ suggests that adsorption is not involved in the pyrimidine electrochemical processes on graphite, at least in acidic solution. 
Cytosine. The single 3-electron cytosine peak is due to a succession of three processes: (1) 2-electron electrochemical reduction of the $3,4 \mathrm{~N}=\mathrm{C}$ bond (this is a combination of the first two 1-electron processes seen in pyrimidine), (2) rapid deamination of the reduction product to 2-hydroxypyrimidine, and (3) 1-electron electrochemical reduction of the latter, similar to pyrimidine, to a free radical, which dimerizes under the experimental conditions before it can be further reduced. ${ }^{10}$

The single reduction peak observed at the HMDE gives no evidence for reversibility. The close agreement of the variation of $E_{\mathrm{p}}$ with $\mathrm{pH}$ with that of $E_{1 / 2}$ at the $\mathrm{DME}^{8,10}$ and the constancy of $i_{\mathrm{p}}$ over the $\mathrm{pH}$ range, which is in accord with the constant diffusion current constant at the DME, suggest identical mechanisms.

The $i_{\mathrm{p}} / A C$ ratio for cytosine, purine peak $\mathrm{I}$ and adenine are in ratio $1 \cdot 7: 1 \cdot 0: 3 \cdot 5$ at $0.026 \mathrm{~V} / \mathrm{sec}$; and $1 \cdot 2: 1 \cdot 0: 3 \cdot 2$ at $0 \cdot 26 \mathrm{~V} / \mathrm{sec}$. These ratios are in fair agreement with earlier coulometrically measured faradaic $n$ values of 3,2 and 6 respectively, for cytosine, purine wave I and adenine., ${ }^{9,10}$

Purine. Purine exhibits two $\mathrm{pH}$-dependent polarographic waves in acidic solution (ca. $\mathrm{pH} 2-5.5)$ at the DME9. Wave I $\left(E_{1 / 2}=-0.697-0.083 \mathrm{pH}\right)$ is due to 2electron reduction to 1,6-dihydropurine, wave II $\left(E_{1 / 2}=-0.902-0.080 \mathrm{pH}\right)$ is due to a further 2-electron reduction, probably to 1,2,3,6-tetrahydropurine, which hydrolyses to a 4-aminoimidazole.

The two cathodic peaks seen at the HMDE are due to identical processes as indicated by the close agreement between $E_{\mathrm{p}}$ and $E_{1 / 2}$. The cyclic voltammetric behaviour gives little evidence of reversibility, although oxidation of the unstable reduction product of peak II could be detected at very fast scan rates as a small anodic peak. The constancy of the peak currents to above $\mathrm{pH} 9$, at which peak II disappears, contradicts earlier DME studies. ${ }^{9}$ Re-examination of purine at the DME, as previously described, showed no diminution of the limiting current for waves I and II up to $\mathrm{pH} \mathrm{9}$; wave I persisted to even higher $\mathrm{pH}$ values.

The $i_{\mathrm{p}}$ for the single cathodic peak observed on cyclic voltammetry at the PGE is relatively constant to $\mathrm{pH} 9 ; i_{\mathrm{p}}$ for the anodic peak, which is about one-third of that for the cathodic peak, is remarkably constant. Above $\mathrm{pH} 9$, where the cathodic peak disappears beyond the background discharge, the anodic $i_{\mathrm{p}}$ drops slightly owing to the cathodic background reactions in the potential range involved.

The process giving rise to the single PGE cathodic peak most likely corresponds to the wave I process observed at the HMDE, as evidenced by the similar $\mathrm{pH}$-dependence at both electrodes, although the peak always occurred at somewhat more negative potential at the PGE than at the HMDE. Such behaviour is indicative of adsorption or, at least, of more pronounced adsorption on graphite than on mercury, which would tend to inhibit the reduction process owing to the lower activity of the electroactive purine species in the adsorbed state. ${ }^{14.22}$ Smith and Elving ${ }^{9}$ reported that the product of the first 2-electron process at mercury is fairly stable in aqueous solution in the absence of oxygen; hence the oxidation peak observed on the reverse sweep at the PGE is due to the reoxidation of the product of the cathodic process and the overall cathodic-anodic process is

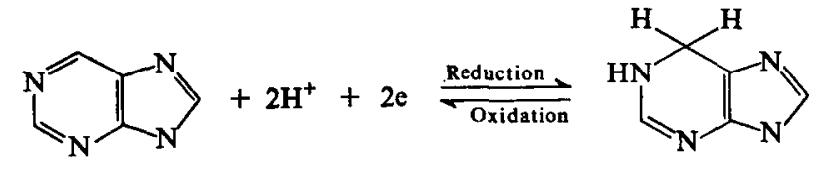


The exponential current-concentration relations at the PGE are further evidence for adsorption. The absence of a second cathodic peak at the PGE can be attributed to the smaller potential range available at the PGE.

Adenine. Reduction of adenine at mercury electrodes involves an overall 6-electron reduction: 2-electron hydrogenation of the 1,6 double bond, followed by 2electron reduction of the 2,3 double bond, deamination at the 6-position, further 2-electron reduction of the consequently regenerated 1,6 double bond and hydrolytic cleavage at the 2,3 position to give the same product as the overall 4 -electron purine reduction. ${ }^{10}$

Adenine gives a single anodic wave at the PGE, from $2 M$ sulphuric acid medium to pH 9; the half-peak potential varies from 1.34 to $0.74 \mathrm{~V} .12$

The single cathodic peak observed for adenine at the HMDE has no anodic counterpart. The pH-dependence and the large peak current suggest that the peak corresponds to the DME wave. ${ }^{9}$

The ratio of $i_{\mathrm{p}} / A C$ for adenine to that for purine peak $\mathrm{I}$ is 3.5 at $0.026 \mathrm{~V} / \mathrm{sec}$ and 3.2 at $0.26 \mathrm{~V} / \mathrm{sec}$, which is in good accord with six electrons being involved in the adenine reduction and two in the purine reduction as discussed under cytosine.

The single oxidation peak observed for adenine on cyclic voltammetry at the PGE corresponds to that observed at slow single sweep voltammetry. ${ }^{12}$ The absence of a reduction peak is again related to the smaller negative potential range available at graphite. The exponential decrease in the $i_{\mathrm{p}} / A C$ ratio with increasing concentration, especially at $0.6 \mathrm{~V} / \mathrm{sec}$, is indicative of adsorption. The $i_{\mathrm{p}} / A C$ ratio often decreased appreciably at the PGE, even at $0.06 \mathrm{~V} / \mathrm{sec}$, in agreement with the previously noted ${ }^{12}$ slight decrease in the $i_{\mathrm{p}} / C$ ratio in $\mathrm{pH} 4.7$ acetate medium from 79 to $72 \mu \mathrm{A} .1 . \mathrm{mmole}{ }^{-1}$ over a $0 \cdot 2-1.0 \mathrm{~m} M$ concentration range on single-sweep voltammetry. However, as with the purine results, the current-limiting effect could be due to a slow chemical step.

\section{CORRELATION OF ELECTROCHEMICAL BEHAVIOUR \\ AND QUANTUM MECHANICAL PARAMETERS}

The facts that adenine and cytosine are adsorbed on electrodes and produce faradaic a.c. waves, i.e., possess some degree of reversibility, indicate two possible causes for their apparently anomalous relative $E_{1 / 2}$ potentials, as compared to the order predicted from quantum mechanical calculations.

For the energy of the lowest empty molecular orbital (LEMO) to be simply related to $E_{1 / 2}$ for a reduction, the process must be reversible, i.e., $E_{1 / 2}=E_{0}{ }^{\prime}$, where $E_{0}{ }^{\prime}$ is the formal electrode potential (due allowance being made for the ratio of the square roots of the diffusion coefficients of the oxidized and reduced species), since then $E_{1 / 2}$ is simply related to the standard free energy change of the process, $\Delta G^{\circ}$. Any deviation of $E_{1 / 2}$ from $E_{0}{ }^{\prime}$ can be expressed as $E_{1 / 2}=E_{0}{ }^{\prime}+\eta$ where $\eta$ is the overpotential, i.e., the extra energy required to cause the reaction to proceed at a reasonable rate, and, accordingly, is a measure of departure from reversibility. Comparison of the a.c. polarographic current for two closely related compounds, for which the electrochemical processes involve the same number of electrons in the rate-determining step, i.e., $n_{\mathrm{a}}$, and in any subsequent steps contributing to the overall a.c. current, should give a measure of the departure from reversibility for the two compounds, i.e., the extent to which $E_{1 / 2}$ would be expected to differ from $E_{0}{ }^{\prime}$ or the value obtained quantum mechanically from LEMO calculations. 
If the a.c. reductions of adenine and cytosine are assumed to involve an identical number of electrons (either one or possibly two), adenine is reduced far more reversibly than cytosine, $i . e$, the electrode reaction for adenine reduction is far more rapid; hence, the departure of $E_{1 / 2}$ from the order predicted by LEMO values would be less for adenine than for cytosine. Evaluation of the present semiquantitative experimental results in terms of the expected $E_{1 / 2}$ shift with $\mathrm{pH}$ is insufficiently precise to predict with assurance the difference in measured and reversible half-wave potentials.

Although adenine appears to be more strongly adsorbed than cytosine at potentials preceding the regions of faradaic electrochemical activity, the slight base current elevation immediately before these regions suggests that desorption occurs and that adsorption effects are not of major consequence in the energetics of the overall faradaic processes at mercury.

The likely result, therefore, is an overall shift of $E_{1 / 2}$ for adenine to a less negative potential than that of cytosine.

Account should also be taken of the contribution of solvation energy to $E_{1 / 2}$ in correlation of the latter with theoretically calculated LEMO energies. ${ }^{23}$

For a reduction process in solution,

$$
\mathrm{Ox}+n \mathrm{e} \rightleftharpoons \mathrm{Red}
$$

it can be shown that, for a "reversible" polarographic process,

$$
E_{1 / 2}=\frac{-\Delta H^{\circ}}{n F}+\frac{T \Delta S^{\circ}}{n F}-\frac{R T}{n F} \ln \frac{f_{\mathrm{Red}}}{f_{\mathrm{Ox}}}-\frac{R T}{n F} \ln \frac{D_{\mathrm{Ox}}^{1 / 2}}{D_{\mathrm{Red}}^{1 / 2}}
$$

where the symbols have their usual thermodynamic and electrochemical significance. By considering the reactions

$$
\begin{aligned}
& \mathrm{Ox}_{(\mathrm{g})}+n \mathrm{e} \rightleftharpoons \operatorname{Red}_{(\mathrm{g})} \quad \mathrm{EA} \\
& \mathrm{Ox}_{\text {(soln) }}+n \mathrm{e} \rightleftharpoons \operatorname{Red}_{(\mathrm{soln})} \mathrm{EA}+\left(\mathrm{SE}_{\mathrm{Ox}}-\mathrm{SE}_{\mathrm{Red}}\right)
\end{aligned}
$$

where EA is the electron affinity of the Ox species and SE is the solvation energy of the oxidized and reduced species as designated, and using the approach of Pysh and Yang, ${ }^{23} \Delta H^{\circ}$ in equation (6) can be replaced to give

$$
E_{1 / 2}=\mathrm{EA}+\left(\mathrm{SE}_{\mathrm{Ox}}-\mathrm{SE}_{\mathrm{Red}}\right)+\frac{T \Delta S^{\circ}}{n F}-\frac{R T}{n F} \ln \frac{f_{\mathrm{Red}} D_{\mathrm{Ox}}^{1 / 2}}{f_{\mathrm{Ox}} D_{\mathrm{Red}}^{1 / 2}}
$$

This expression is similar to equation (1) of Pysh and Yang, ${ }^{23}$ although the latter refers to an oxidation process and contains minor error.

The theory of linear combination of atomic orbitals (LCAO) gives the energies of the molecular orbitals of the $\pi$-electrons in the form

$$
E_{\mathrm{i}}=\alpha+\beta k_{\mathrm{i}}
$$

where $\alpha$ is a coulomb integral, $\beta$ a resonance integral and $k_{\mathrm{i}}$ the matrix eigen value. Rewriting equation (9) and neglecting the small entropy and logarithmic terms,

$$
E_{1 / 2}=\beta k_{\mathrm{i}}+\left(\mathrm{SE}_{\mathrm{Ox}}-\mathrm{SE}_{\mathrm{Red}}\right)+\mathrm{constant}
$$

Then, plots of $E_{1 / 2} v s$. the LEMO energy (usually, $k_{\mathrm{i}}$ expressed in units of $\beta$ ) should be linear, provided that for the series of compounds studied the solvation energy terms 
between members of the series are constant or vary in a regular fashion. It is unlikely that the latter would be true for the different purines and pyrimidines in aqueous solution because of the variation in nature, number and strength of the hydrogenbonding donor and acceptor groups in the different compounds and in the reduction products derived from them.

However, it is not unlikely that the rate-controlling step for the reduction of each compound might involve only a single electron and that the difference in solvation energies of the reactant and initial product in the rate-controlling step for the first electron transfer for a given compound would be small, if not negligible.

Many of the purines and possibly pyrimidines appear to be reduced only in the protonated state, e.g., adenine, whereas others, e.g., purine and pyrimidine themselves, are reduced in an unprotonated form; this, of course, does not affect the initial or overall electron consumption, although significant solvation energy differences might be involved.

\section{ANALYTICAL IMPLICATIONS AND APPLICABILITY}

A particularly difficult problem in many in vivo studies of purines and pyrimidines is the availability of suitably selective and sensitive methods for their determination. No completely satisfactory method for the determination of even the oxypurines and pyrimidines has ever been developed; ${ }^{24}$ for example, it is difficult to determine xanthine in the presence of hypoxanthine. Accordingly, the present study has been used to define the analytical applicability of cyclic voltammetry and alternating current polarography for the determination of individual purines and pyrimidines and the analysis of mixtures.

Cyclic voltammetry at $H M D E$. The concentration studies on the four purines and pyrimidines examined in detail indicates an accuracy of $2-3 \%$ relative. The time necessary for a determination is considerably less than for DME polarography.

The data on cytosine, in particular, showed that at $0.26 \mathrm{~V} / \mathrm{sec}$ scan rate the peaks are much better formed and easier to measure than at lower scan rates; this suggests that, for compounds which give slow scan voltammetric peaks very close to background discharge, necessitating point-by-point background current subtraction, fast scan cyclic voltammetry could provide, on occasion, a rapid and convenient analytical method.

Cyclic voltammetry at PGE. Generally, current reproducibility at the PGE was poor, due, at least in part, to adsorption phenomena, since purine and adenine, which gave non-linear $i_{\mathrm{p}}-C$ curves, also showed very poor reproducibility; pyrimidine, which gave linear relations, showed far better reproducibility. It is likely that with each resurfacing of the electrode different numbers of active adsorption sites are exposed, which in turn would give rise to differing current values. Adsorption apart, the agreement between replicate determinations, even for pyrimidine where apparently adsorption is not pronounced, is somewhat inferior to that for the HMDE, especially at fast scan rates; again, the conclusion is that poor surface area reproducibility is probably responsible.

Of particular interest was the behaviour of purine for which even at $\mathrm{pH}$ values where the cathodic peak disappeared against the background discharge, an anodic peak could still be observed on the return scan; this indicates that it is possible, utilizing cyclic voltammetry, to determine purine and probably many other compounds 
under conditions where they appear by single-sweep methods to be non-electroactive. Significantly, the anodic purine-product wave did not decrease appreciably in height even when the purine cathodic peak must have occurred several hundred $\mathrm{mV}$ beyond the onset of background discharge, e.g., for $\operatorname{lm} M$ purine, the current was constant in the $\mathrm{pH}$ range 9-12.

A.c. polarography. The analytical implications of the a.c. polarographic behaviour of purines and pyrimidines are obvious, e.g., it would be a relatively simple matter to determine these compounds in the presence of other compounds which posses no degree of a.c. polarographic reversibility. The sensitivity is quite high; the lower limit is $0.1 \mathrm{~m} M$ or lower, depending on the sensitivity of the current-measuring device employed.

\section{CONCLUSIONS}

Cyclic voltammetry at the HMDE gives results comparable to those obtained at DME, indicating that earlier proposed mechanistic routes for purine, adenine, pyrimidine and cytosine are generally correct. In contradiction to earlier studies, purine is polarographically reducible at $\mathrm{pH}$ values up to well above 9.

Electrocapillary curve measurement and a.c. polarography indicate that purine, adenine, adenosine, adenosine phosphates and cytosine are adsorbed at the DME. Since all of these compounds appear to be desorbed before faradaic reduction, it is unnecessary to consider adsorption in the overall energetics of the polarographic reduction. With the exception of cytosine, none of the pyrimidines examined is adsorbed at the DME.

A.c. polarography of the purines and pyrimidines studied indicates them to be reduced in only slightly reversible processes.

The very marked difference in height of the a.c. polarographic waves for adenine and cytosine indicates that, if solvation energy effects are neglected, the disagreement between quantum mechanical prediction and polarographic observation regarding the ease of reduction of these compounds is due to marked differences in electrochemical reversibility, i.e., electrode kinetics favour the more ready reduction of adenine.

Purine and adenine or their electrochemical reduction products are probably strongly adsorbed at the graphite electrode, which explains the prolonged electrolysis time required for macroscale electro-oxidation of adenine. ${ }^{3}$

Cyclic voltammetry and a.c. polarography provide potentially useful approaches for the determination of purines and pyrimidines.

\section{Reagents EXPERIMENTAL}

Buffer solutions were prepared from analytical reagent grade chemicals. Nitrogen used for deoxygenating was purified and equilibrated by bubbling it successively through acidic vanadium(II) chloride solution kept over heavily amalgamated zinc, saturated calcium hydroxide solution and distilled water.

\section{Apparatus}

Triangular potential sweep voltammetry (cyclic voltammetry) was carried out with an apparatus essentially as described by Schwarz and Shain. ${ }^{25}$ Cyclic voltammograms were recorded on a Moseley Model 135 X-Y recorder.

A.c. polarography was carried out by modifying the cyclic voltammetry unit as described by Smith. ${ }^{26}$ The applied d.c. potential was obtained from a potentiometer employing a $2 \cdot 7 \mathrm{~V}$ mercury battery. The a.c. signal was generated with a Hewlett-Packard Model 202A function generator. All a.c. polarograms were recorded manually; the alternating current (rms) was measured with HewlettPackard Model 400D vacuum tube voltmeter. In order to eliminate high-frequency noise generated in the operational amplifier circuits, the cell signal was filtered through a suitable low-pass filter ${ }^{27}$ before mcasurement. 
A conventional three-electrode cell was employed. The pyrolytic graphite electrode (PGE) was prepared as described previously. ${ }^{28}$ A normal hanging mercury drop electrode (HMDE) was prepared as described previously. ${ }^{28}$

Because preliminary electrocapillary studies had indicated rather erratic variation of the DME drop-time at very negative potentials and often also in the presence of the electroactive compounds at less negative potentials, the capillary was silaned. The most successful procedure was to draw dichlorodimethylsilane vapour through a length of clean capillary for a few minutes, followed by air for a further $30 \mathrm{~min}$; the top of the capillary was then broken off. Unfortunately, this silanation deteriorated and, after some days, a new capillary had to be prepared. Accordingly, in some of the later electrocapillary work, the capillary was silaned by immersing it for a few minutes in Beckmann Desicote with the mercury drops falling, allowing the excess Desicote to drain off and washing the top with acetone and water; the electrode then appeared to be suitable for use, i.e., stable drop-times were obtained at least up to about $-1.2 \mathrm{~V}$.

Capillary characteristics of the DME used for a.c. polarography are presented where appropriate in the text.

\section{General voltammetric procedures}

Test solutions were prepared by diluting appropriate quantities of stock solutions (prepared by dissolving weighed quantities in distilled water and diluting to a known volume) with suitable buffer solution. Solutions were always deoxygenated for at least $10 \mathrm{~min}$ before examination. Buffer and background solutions were of the same types as used in reference 9. All test solutions had an ionic strength of $0.5 M$.

The PGE and HMDE were always left for about $30 \mathrm{sec}$ in the test solution to allow equilibration before the voltammetric scan was begun.

For a.c. polarography, an applied a.c. frequency of $50 \mathrm{~Hz}$ and $4 \mathrm{mV}(\mathrm{rms})$ amplitude was employed unless otherwise stated; readings were taken at every $10 \mathrm{mV}$. Although an $\mathrm{Hg} / \mathrm{Hg}_{2} \mathrm{SO}_{4}$ reference electrode (MSE) was used at positive potentials $v s$. SCE, all potentials cited are referred to the SCE at $25^{\circ}$, unless otherwise specified.

\section{Reproducibility and compatibility of data}

Current measurements on cyclic voltammetry at the HMDE were reproducible to $2-3 \%$ relative. The poor precision on cyclic voltammetry at the PGE is to be associated with the specific compounds involved; satisfactory precision has been reported by the authors and others for different compounds.

Reproducibility of potential at the PGE was more satisfactory than that of current, being about $\pm 25 \mathrm{mV}$; it was $\pm 10 \mathrm{mV}$ at the HMDE.

It is difficult to compare decomposition potentials at graphite and mercury electrodes because of the differing magnitude of the respective charging currents and the rapidity with which the current rises at the PGE as compared to the HMDE. An estimate of the decomposition potential, i.e., the potential at which the current is $5 \mu \mathrm{A}$ above the extrapolated residual current, in $\mathrm{pH} 4.6$ acetate solution at a scan rate of $0.10 \mathrm{~V} / \mathrm{sec}$ would be $-1.23 \mathrm{~V}$ at PGE (area $12 \mathrm{~mm}^{2}$ ) and $-1.36 \mathrm{~V}$ at HMDE (area $5 \mathrm{~mm}^{2}$ ).

Acknowledgement-The authors thank the National Science Foundation, which helped support the work described.

Zusammenfassung-Um die große Diskrepanz zwischen der leichten polarographischen Reduzierbarkeit von Adenin und Cytosin im Experiment und der durch molecular orbital-Berechnung vorhergesagten näher $\mathrm{zu}$ untersuchen, wurde das elek trochemische Oxidationsund Reduktionsverhalten von Pyrimidin, Cytosin, Purin, Adenin und verwandten Verbindungen sowohl an Quecksilber- als auch an Graphitelektroden studiert. Es ergaben sich Informationen über die spezifische Adsorption von Reaktanten und Produkten an der Elektrode, die Reversibilität des energiekontrollierenden Elektronenübergangsschrittes und begleitende chemische Reaktionen. Dreiecksvoltammetrie, Wechselstrom- und Gleichstrompolarographie und Elektrokapillardaten wurden im einzelnen verwendet. Die ersten drei Verfahren wurden auf ihren eventuellen analytischen Nutzen hin kritisch geprüft. Die Ergebnisse wurden mit früher erhaltenen elektrochemischen Daten verglichen und die Abfolge der Schritte mit Elektroncnübcrgang und der vielen ohne Elektronenübergang wurde besser festgelegt. Es wurde klar, daß zur gültigen Korrelation von quantenmechanisch berechneten Daten über die Energie, die man zur Zufügung oder 


\begin{abstract}
Wegnahme eines Elektrons zu oder von dem äußersten Elektronenzustand des Moleküls (in der Gasphase) braucht, mit elektrochemischen Redoxpotentialen (in Lösung) die Efrekte der Adsorption, der Reversibilität des Elektronenübergangs und die Solvatationsenergie berücksichtigt werden müssen.
\end{abstract}

Résumé-Afin d'évaluer la différence remarquable entre la facilité expérimentale de réduction polarographique de l'adénine et de la cytosine et celle prédite par le calcul d'orbitale moléculaire, on a étudié le comportement à l'oxydation-réduction électrochimique des pyrimidine, cytosine, purine, ađénine et composés apparentés sur électrodes de mercure et de graphite. On a obtenu des informations sur l'adsorption spécifique du réactant et de l'espèce sur l'électrode, sur la réversibilité du stade de transfert électronique régulateur d'énergie et sur les réactions chimiques concomitantes. On a utilisé en particulier la voltammétrie de balayage triangulaire, la polarographie à courants alternatif et continu et des données électrocapillaires. Les trois premières techniques ont été examinées de manière critique quant à leur utilité analytique potentielle. On a comparé les résultats à des données électrochimiques antérieurement obtenues et l'on a établi plus solidement la séquence des stades de transfert électronique et de divers transferts non électroniques. Il est devenu clair que, dans le but de relier de façon valable les données calculées par la mécanique quantique pour l'énergie requise pour ajouter un électron au niveau électronique externe de chaque molecule (en phase gazeuse) ou l'en soustraire, et les potentiels redox électrochimiques (en solution), il faut prendre en considération les influences de l'adsorption, de la réversibilité du transfert électronique et de l'énergie de solvatation.

\title{
REFERENCES
}

1. W. A. Struck and P. J. Elving, Biochem., 1965, 4, 1343.

2. G. Soberon and P. P. Cohen, Arch. Biochem. Biophys. 1963, 103, 331.

3. G. Dryhurst and P. J. Elving, J. Electrochem. Soc., 1968, 115, 1014.

4. J. B. Wyngaardent and J. T. Dunn, Arch. Biochem. Biophys., 1957, 70, 150.

5. F. Bergmann and S. Dikstein, J. Biol. Chem., 1956, 223, 765.

6. B. Pullman and A. Pullman, Quantum Biochemistry, Interscience, New York, 1963.

7. H. Berthod, C. Giessner-Prettre and A. Pullman, Theoret. Chim. Acta, 1966, 5, 53.

8. P. J. Elving, W. A. Struck and D. L. Smith, Mises Point Chem. Anal. Org. Pharm. Bromatol., $1965,14,141$.

9. D. L. Smith and P. J. Elving, J. Am. Chem. Soc., 1962, 84, 1412.

10. Idem, ibid., 1962, 84, 2741.

11. W. A. Struck and P. J. Flving, ibid., 1964, 86, 1229.

12. D. L. Smith and P. J. Elving, Anal. Chem., 1962, 34, 930.

13. J. E. O'Reilly and P. J. Elving, private communication.

14. P. Delahay, New Instrumental Methods in Electrochemistry, Interscience, New York, 1954.

15. R. S. Nicholson and I. Shain, Anal. Chem., 1964, 36, 706.

16. V. Vetterl, Abhandl. Deut. Akad. Wiss., Kl. Med., 1966, 493.

17. Idem, Collection Czech. Chem. Commun., 1966, 81, 2105.

18. T. Biegler, Ph.D. Thesis, University of Sydney, 1962.

19. T. R. Harkins and H. Freiser, J. Am. Chem. Soc., 1958, 80, 1132.

20. G. E. Cheney, H. Freiser and Q. Fernando, ibid., 1959, 81, 2611.

21. I. Bayer, E. Posgay and P. Majlat, Pharm. Zentralhalle., 1962, 101, 476.

22. L. Meites, Polarographic Techniques, 2nd Ed., pp. 187-9. Intersciencc, New York, 1965.

23. E. S. Pysh and N. C. Yang, J. Am. Chem. Soc., 1963, 85, 2124.

24. M. E. Balis, in Advances in Clinical Chemistry, Vol. 10, eds. O. Godansky and C. P. Stewart, Academic Press, New York, 1967.

25. W. M. Schwarz and I. Shain, Anal. Chem., 1963, 35, 1770.

26. D. E. Smith, ibid., 1963, 35, 1811.

27. H. V. Malmstadt, E. G. Enke and E. C. Toren, Electronics for Scientists, p. 563. Benjamin, New York, 1963.

28. L. Chuang, I. Fried and P. J. Elving, Anal. Chem., 1964, 36, 2426.

29. H. Breyer and H. H. Bauer, Alternating Current Polarography and Tensammetry, Interscience Publishers, New York, 1963.

30. D. Britz and H. H. Bauer, Electrochim. Acta, 1968, 13, 347. 